\title{
Monocyte Subsets Have Distinct Patterns of Tetraspanin Expression and Different Capacities to Form Multinucleate Giant Cells
}

\author{
Thomas C. Champion 1,2, Lynda J. Partridge ${ }^{3}$, Siew-Min Ong ${ }^{2}$, Benoit Malleret ${ }^{2,4}$, \\ Siew-Cheng Wong ${ }^{2,4 t}$ and Peter N. Monk ${ }^{1 * t}$
}

${ }^{1}$ Department of Infection, Immunity and Cardiovascular Disease, University of Sheffield, Sheffield, United Kingdom, ${ }^{2}$ Singapore Immunology Network, Agency for Science, Technology and Research, Singapore, Singapore, ${ }^{3}$ Department of Molecular Biology and Biotechnology, University of Sheffield, Sheffield, United Kingdom, ${ }^{4}$ Department of Microbiology and Immunology, Yong Loo Lin School of Medicine, National University of Singapore, National University Health System, Singapore, Singapore

Monocytes are able to undergo homotypic fusion to produce different types of multinucleated giant cells, such as Langhans giant cells in response to M. tuberculosis infection or foreign body giant cells in response to implanted biomaterials. Monocyte fusion is highly coordinated and complex, with various soluble, intracellular, and cell-surface components mediating different stages of the process. Tetraspanins, such as CD9, CD63, and CD81, are known to be involved in cell:cell fusion and have been suggested to play a role in regulating homotypic monocyte fusion. However, peripheral human monocytes are not homogenous: they exist as a heterogeneous population consisting of three subsets, classical $\left(C D 14^{++} C D 16^{-}\right)$, intermediate $\left(C D 14^{++} C D 16^{+}\right)$, and nonclassical $\left(\mathrm{CD} 14^{+} \mathrm{CD} 16^{+}\right)$, at steady state. During infection with mycobacteria, the circulating populations of intermediate and non-classical monocytes increase, suggesting they may play a role in the disease outcome. Human monocytes were separated into subsets and then induced to fuse using concanavalin A. The intermediate monocytes were able to fuse faster and form significantly larger giant cells than the other subsets. When antibodies targeting tetraspanins were added, the intermediate monocytes responded to anti-CD63 by forming smaller giant cells, suggesting an involvement of tetraspanins in fusion for at least this subset. However, the expression of fusion-associated tetraspanins on monocyte subsets did not correlate with the extent of fusion or with the inhibition by tetraspanin antibody. We also identified a CD9High and a CD9Low monocyte population within the classical subset. The CD9High classical monocytes expressed higher levels of tetraspanin CD151 compared to CD9Low classical monocytes but the CD9 ${ }^{\text {High }}$ classical subset did not exhibit greater potential to fuse and the role of these cells in immunity remains unknown. With the exception of dendrocyte-expressed seven transmembrane protein, which was expressed at higher levels on the intermediate monocyte subset, the expression of fusion-related proteins between the subsets did not clearly correlate with their ability to fuse. We also did not observe any clear correlation between giant cell formation and the expression of pro-inflammatory or fusogenic cytokines. Although tetraspanin expression appears to be important for the fusion of intermediate monocytes, the control of multinucleate giant cell formation remains obscure.

Keywords: monocyte, tetraspanin, cd9, fusion, monocyte subsets 


\section{INTRODUCTION}

Human monocytes are able to migrate from the bloodstream into the tissues and differentiate into macrophages and monocytederived dendritic cells (1). They are important in defense against various pathogens (2) but are also implicated in autoimmune and inflammatory diseases (3). Blood monocytes are heterogeneous and three subsets have been defined: classical $\left(\mathrm{Cl}, \mathrm{CD} 14^{++} \mathrm{CD} 16^{-}\right)$, intermediate (Int, $\left.\mathrm{CD} 14^{++} \mathrm{CD} 16^{+}\right)$, and non-classical $(\mathrm{NCl}$, $\mathrm{CD} 14^{+} \mathrm{CD} 16^{+}$), comprising $\sim 85,5$, and $10 \%$ of the total, respectively $(3,4)$. Investigation of the maturation and differentiation kinetics of labeled human monocytes in vivo suggests that they mature from $\mathrm{Cl}$ to Int and then to $\mathrm{NCl}(5,6)$. The subsets differ in their gene expression profiles, cell surface markers, and cytokine secretion (7-11). The blood populations of the Int and $\mathrm{NCl}$ have been observed to be increased in patients with tuberculosis (12) and rheumatoid arthritis (13), whereas Int numbers are increased in various other inflammatory conditions, including Crohn's disease (14), sarcoidosis (15), and cardiac disease (16, 17).

Under certain circumstances, monocytes and macrophages are able to fuse to form multinucleated giant cells (MGC), such as the osteoclast MGC that remodel and maintain bone homeostasis (18). Monocytes can form inflammatory MGC, such as Langhans giant cells (LGC), in response to M. tuberculosis infections during granuloma formation around infected macrophages (19). Monocytes can also fuse in response to non-phagocytosable foreign material such as medical implants, forming foreign body giant cells (FBGC) (20).

The mechanism of monocyte fusion is still largely unknown and only a handful of essential proteins have been identified $(21,22)$. Furthermore, LGC and FBGC formation appears to be initiated by different cytokines, IFN $\gamma$ and IL-4, respectively, which could suggest that they coordinate fusion through multiple signal transduction pathways $(23,24)$. Monocytes activated by fusogenic stimuli secrete chemokines, such as CCL2 and CCL3, upregulate cell-cell adhesion proteins (LFA-1, ICAM-1, and E-cadherin) (25) and fusion-facilitating proteins, such as CD200 (26), SIRP $\alpha /$ CD172a/MFR (27), CD47 (28), CD36 (29), CD62E (E-selectin) (30), matrix metallopeptidase 9 (MMP9) (31), and dendrocyteexpressed seven transmembrane protein (DC-STAMP) $(32,33)$.

The tetraspanin family of membrane proteins has been implicated in the regulation of several different types of cell-cell fusion, including CD9, CD81, and CD151 in sperm-egg interactions (34), CD9 and CD81 in muscle cell fusion (35), CD82 in HTLV-1 syncytial formation (36) and CD9 in HIV-1-induced cell fusion (37). Osteoclast formation is known to be regulated by CD9, Tspan-5, and Tspan13 (38, 39). In experimental systems using concanavalin A (ConA)-induced fusion, anti-tetraspanin antibodies against CD9, CD81, CD151, and CD63 have been shown

\footnotetext{
Abbreviations: ConA, concanavalin A lectin; MGC, multinucleated giant cell; $\mathrm{Cl}$, classical monocyte sybset; $\mathrm{NCl}$, non-classical monocyte subset; Int, intermediate monocyte subset; LGC, Langhans giant cell; SGC, syncytial giant cell; FBGC, foreign body giant cell; FI, fusion index; MACS, magnet-activated cell sorting; DC-STAMP, dendrocyte-expressed seven transmembrane protein; SEM, scanning electron microscopy; MFI, median fluorescence intensity; MMP9, matrix metallopeptidase 9 .
}

to inhibit or enhance the formation of MGC (40-42). Importantly, many of the fusion regulatory proteins implicated in MGC formation have been shown to be associated with tetraspanins in the plasma membrane (43).

Recently, CD9, CD53, CD63, and CD81 were shown to be expressed differently on the three monocyte subsets (44), indicating that subsets may have different fusion behaviors. In this study, we have investigated the propensities of the monocyte subsets for fusion, and attempted to correlate this with the expression of a group of fusion-related tetraspanins, fusion proteins, and cytokines. Further understanding of the contribution of monocyte subsets to fusion and the role tetraspanins play in the fusion process may help develop treatments for granulomatous diseases such as tuberculosis and inhibit foreign body reactions during medical implant rejection.

\section{MATERIALS AND METHODS}

\section{Cells}

All experiments used human blood monocytes collected in EDTA. For experiments using purified monocyte subsets, cells were obtained from apheresis cones donated by anonymous platelet donors in Singapore. Blood samples and experimental procedures were approved by the Institutional Review Board, Singapore, in accordance to guidelines of the Health Science Authority of Singapore (Reference code: NUS-IRB10-250). Informed written consent was obtained from participants for this study in accordance with the Declaration of Helsinki. Apheresis cones contain approximately $400-1,200 \times 10^{6}$ cells per cone, of which $\sim 68 \%$ are lymphocytes, $\sim 25 \%$ monocytes, $\sim 5 \%$ neutrophils, $\sim 2 \%$ basophils, and $<1 \%$ eosinophils (45).

\section{Monocyte Purification}

Human blood from apheresis cones was diluted 1:1 in Dulbecco's phosphate buffered saline without $\mathrm{Ca}^{2+}$ and $\mathrm{Mg}^{2+}$ (Lonza). Diluted blood was separated on Ficoll-Paque PLUS (GE Healthcare Life Sciences) by centrifugation. The PBMC layer was removed and washed with saline to remove platelets. Red blood cells were lysed and cell number and viability determined by counting in the presence of Trypan Blue (Sigma-Aldrich). Total monocytes were positively selected using anti-CD14-beads according to manufacturer's instructions (Miltenyi Biotec). The purity as determined by flow cytometry, and viability by Trypan blue exclusion were consistently $>90 \%$. In some cases, monocytes were also purified by adherence to plastic, as described previously (41). Monocytes for subsequent subset fractionation were first enriched by depleting non-monocytic cells using magnet-activated cell sorting (MACS) with anti-CD3 and anti-CD19-beads, according to manufacturer's instructions (Miltenyi Biotec). MACS-enriched monocytes contained typically $69 \%$ monocytes. For FACS purification of monocyte subsets, a cocktail containing anti-CD14-efluor450 (eBioscience), anti-CD16-FITC (Miltenyi Biotec), and anti-CD56-APC (BD Biosciences) was added to the MACS-enriched total monocytes. Contaminating NK cells were excluded and monocyte subsets: $\mathrm{Cl}\left(\sim 80 \%\right.$; $\left.\mathrm{CD} 14^{++} \mathrm{CD} 16^{-}\right)$, Int $\left(\sim 8 \%\right.$; $\left.\mathrm{CD} 14^{++} \mathrm{CD} 16^{+}\right)$, and $\mathrm{NCl}\left(\sim 11 \% ; \mathrm{CD} 14^{+} \mathrm{CD} 16^{++}\right)$ 
were gated based on the gating strategy shown in Figure S1 in Supplementary Material. To maintain reproducibility, subsets were always gated with equal sized square gates with perpendicular borders. A post-sort check was conducted in every subset to ensure that the purity of each subset was $\geq 90 \%$.

\section{Fusion Assays}

FACS-purified monocyte subsets were seeded at $1.5 \times 10^{5}$ cells per $31.65 \mathrm{~mm}^{2}$ well to give a cell density of 4,739 monocytes $\mathrm{mm}^{-2}$. Within an hour of seeding, ConA from Canavalia ensiformis (Sigma-Aldrich) was added at $10 \mu \mathrm{g} \mathrm{ml}^{-1}$ in IMDM (Lonza) containing human AB Serum (Innovative Research, Inc., IPLASERAB) and penicillin/streptomycin (Biological Industries). Monocyte subsets were incubated for up to $72 \mathrm{~h}$ at $37^{\circ} \mathrm{C}$ in $5 \%$ $\mathrm{CO}_{2}$ for all fusion assays. The supernatant from each well was collected and stored at $-80^{\circ} \mathrm{C}$ for cytokine measurements. Cells were stained with nucleus/actin staining solution containing $3 \mu \mathrm{g} \mathrm{ml}^{-1}$ DAPI (ThermoFisher) and $1 \mu \mathrm{g} \mathrm{ml}^{-1}$ Phalloidin-TRITC (ThermoFisher) overnight at $4^{\circ} \mathrm{C}$ in the dark. The cells were then fixed and imaged with an Olympus IX83 inverted microscope running MetaMorph for Olympus imaging software (Olympus, UK). MGC were identified from the image Stack on FIJI ImageJ and freehand outlines were drawn around each MGC (defined as cells with $\geq 3$ nuclei) to make Region Of Interest coordinates that could be saved alongside the Stack files. The DAPI stack and ROI list file were loaded in Image J before using a selection on user-generated macros to count the nuclei per MGC, MGC area and the total number of nuclei per field. MGC types were designated using the criteria outlined in Figure S2 in Supplementary Material. LGC and FBGC are known types of MGC but a third category was also detected in our studies, which we termed the syncytial giant cell (SGC). SGC are characterized by having no clear organization of nuclei and with patchy staining for polymerized actin (Figure S2 in Supplementary Material). In all cases, the total nuclei counted in single and fused cells were much lower than the number originally plated. The missing nuclei were designated as "Detached Cells" but the fate of these cells was not investigated further.

\section{Measurement of Tetraspanin and Fusion Protein Expression by Flow Cytometry}

A 10-marker panel was developed that could identify the three monocyte subsets, quantify the expression of seven tetraspanins and detect cell viability all in one sample (Table S1A in Supplementary Material). The panel consisted of a LIVE/DEAD Blue dye, two monocyte subset markers (anti-CD14- PE-CF594 and anti-CD16- PE-Vio770) and tetraspanins (anti-CD9-Biotin, anti-CD37-APC, anti-CD53-CF405M, anti-CD63-PerCP, antiCD81-Alexa Fluor 700, anti-CD82-PE, anti-CD151-FITC). Strepavidin-APC-Cy7 was used as the secondary reporter for CD9-Biotin. To detect changes after ConA treatment, adherent monocytes were treated with or without ConA for $4 \mathrm{~h}$ (at which point monocyte fusion can be observed), and then harvested by scraping prior to antibody staining, as above. A compensation matrix was generated on FACSDiva software using negative control or capture anti-mouse Fc compensation beads for all fluorophore combinations. In separate experiments, fusion protein antibodies were used individually on freshly isolated monocytes, with a FITC-labeled secondary antibody, using the CD14/CD16 antibody pair to distinguish subsets. In all cases, antibodies were individually titrated to ascertain the concentration for optimum binding and compared to an appropriate isotype control antibody. Flow acquisition was performed on a BD LSR II.

\section{Median Nuclei per MGC}

The number of nuclei per MGC had a positive skew whereby smaller (3-8 nuclei) MGC were far more common than larger ( $\geq 20$ nuclei) MGC and so the median was used to describe the average size of a giant cell in any given condition.

\section{Fusion Index (FI)}

Fusion index expresses the fusion of cells as the ratio of nuclei inside fused cells with $\geq 3$ nuclei to the total number of nuclei counted and expressed as a percentage.

\section{Cytokine Assays}

The supernatants collected at 24,48 , and $72 \mathrm{~h}$ from the fusion studies were stored at $-80^{\circ} \mathrm{C}$ before analysis for CCL2 (MCP-1), CCL3 (MIP-1 $\alpha$ ), RANTES, IL- $1 \alpha$, IL-1 $\beta$, TNF $\alpha$, IL-6, IL-17A, IL-4, IL-10, IL-13, GM-CSF, IL-3, IFN $\gamma$, and VEGF, using Lumine ${ }^{\circledR} \mathrm{xMAP}^{\circledR}$ technology and customized human 9- and 15-plex kits (Merck Millipore) with DropArray ${ }^{\mathrm{TM}}$-bead plates (Curiox).

\section{Scanning Electron Microscopy (SEM)}

For imaging by SEM, sorted cells were allowed to adhere for $15 \mathrm{~min}$ at room temperature to glass coverslips pretreated with poly-L-lysine (Sigma), then were fixed for $1 \mathrm{~h}$ at room temperature in $2.5 \%(\mathrm{w} / \mathrm{v})$ glutaraldehyde and $0.1 \mathrm{M}$ phosphate buffer ( $\mathrm{pH} 7.4$ ) and were washed twice in PBS. After fixation for $1 \mathrm{~h}$ at room temperature with $1 \%(\mathrm{w} / \mathrm{v})$ osmium tetroxide (Ted Pella), cells were washed in deionized water and dehydrated with a graded series of ethanol immersions from 25 to $100 \%$, and were dried to the critical point (CPD 030; Bal-Tec). The glass coverslip was then laid on adhesive film on a scanning electron microscope sample holder and was firmly touched with an adhesive sample holder. The surface on which the cells were deposited, as well as the adhesive surface, were both coated with $5 \mathrm{~nm}$ of gold in a high-vacuum sputtering device (SCD005 sputter coater; Bal-Tec). The coated samples were examined with a field emission scanning electron microscope (JSM-6701F; JEOL) at an acceleration voltage of $8 \mathrm{kV}$ with the in-lens secondary electron detector. Fluorescence and brightfield images were also taken and collaged into larger map images using ImageJ FIJI. The brightfield map was compared with the low magnification SEM images to identify the location of the high magnification SEM images. The appropriate high magnification SEM images and 20× magnification fluorescent images were then matched, cropped, and merged using ImageJ.

\section{Statistical Analyses}

All statistical analyses were performed with GraphPad Prism v6.04 and the appropriate tests are noted in the legend of each figure. In all figures the data value represents the number $(n)$ of 
different donor repeats in the experiment, and the SEM is reported where $n \geq 3$, except where stated. All fluorescence-based values [flow cytometry median fluorescence intensity (MFI)] were logtransformed before statistical analysis. ${ }^{*} p \leq 0.05,{ }^{* *} p \leq 0.01$, ${ }^{\star * *} p \leq 0.001,{ }^{* * *} p \leq 0.0001$.

\section{RESULTS}

\section{Monocyte Subsets and MGC Formation}

Human blood monocytes were first negatively selected by removing non-monocytic cells using MACS and then subjected to positive selection for individual subsets using stringent gating based on anti-CD14 and anti-CD16 antibody binding (Figure S1 in Supplementary Material).
Fusion was induced using ConA, a lectin known to stimulate cell fusion in diverse cell types, e.g., Drosophila somatic cells (46). The exact mechanism of ConA facilitated fusion is currently unknown. However, it has been shown that ConA triggers a release of fusion initiating cytokines from mouse macrophages, such as IFN $\gamma$, TNF$\alpha$, IL-1 $\beta$, and IL-4 (47). The behavior of the different subsets during ConA stimulation was determined by counting stained nuclei to provide a measure of the proportions of single and fused cells where the latter refers to cells with $>3$ nuclei (Figure 1). Interestingly, the majority of the monocytes were lost after $72 \mathrm{~h}$, presumably due to detachment and/or cell death. Int monocytes fused more rapidly than $\mathrm{Cl}$ and $\mathrm{NCl}$ subsets, but were also significantly more likely to be dead/detached by 48 and $72 \mathrm{~h}$. Cl monocytes were significantly less likely to fuse than either of the other two subsets, although the differences between subsets became less pronounced over time.
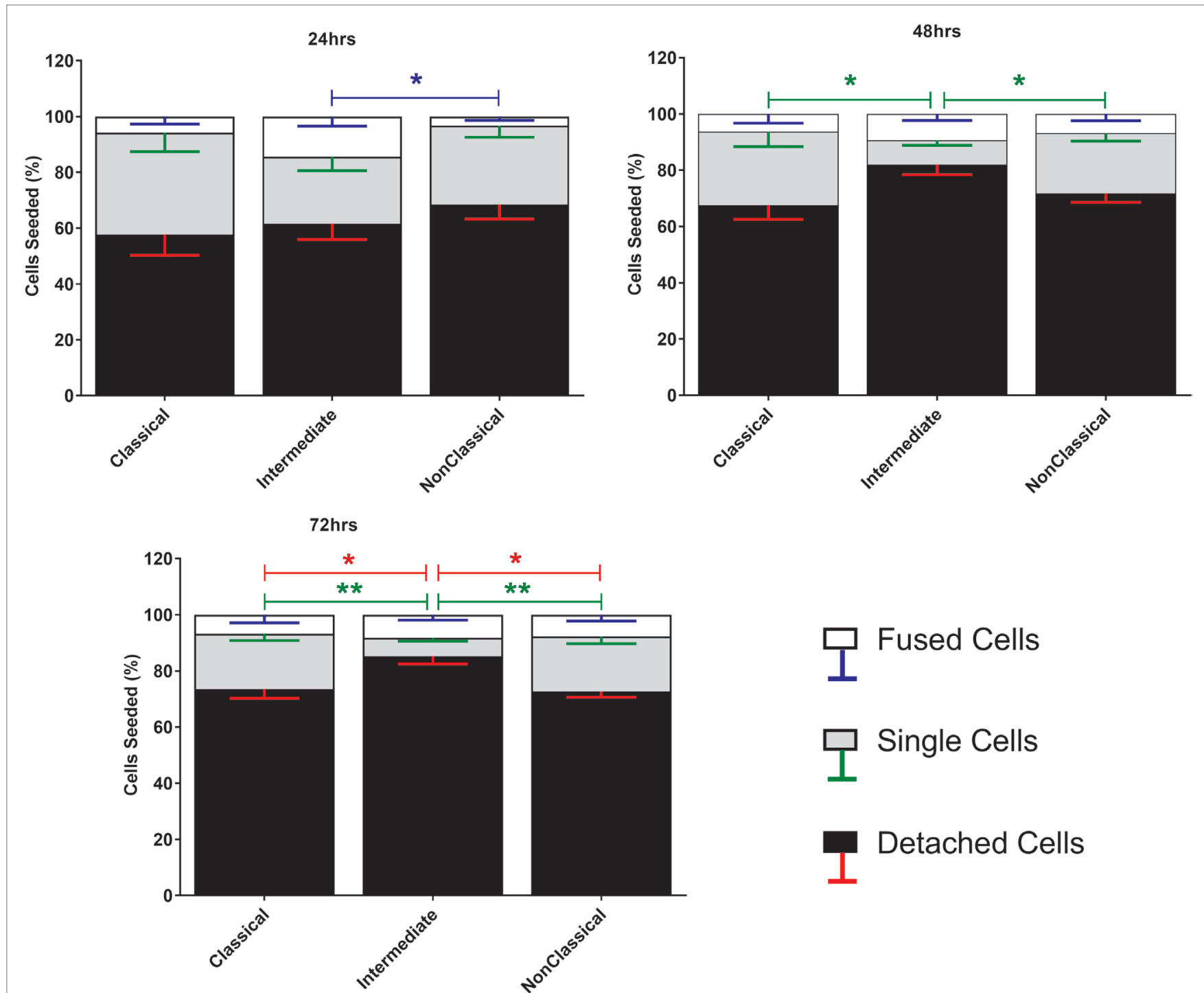

FIGURE 1 | Cell fate during ConA-induced fusion varies between monocyte subsets. The fate of sorted monocyte subsets was determined by counting nuclei at 24 , 48 , and $72 \mathrm{~h}$ and expressed as a percentage of the cell numbers originally plated. Bars represent means \pm SEM, $n=8$. Significance was tested with a KruskalWallis test with a Dunn's multiple comparisons test comparing the means of the same fate and time point against the other subsets. Black bars/red error bars: detached cells, gray bars/green error bars: single cells and white bars/blue error bars: fused cells with $>3$ nuclei. 


\section{A}

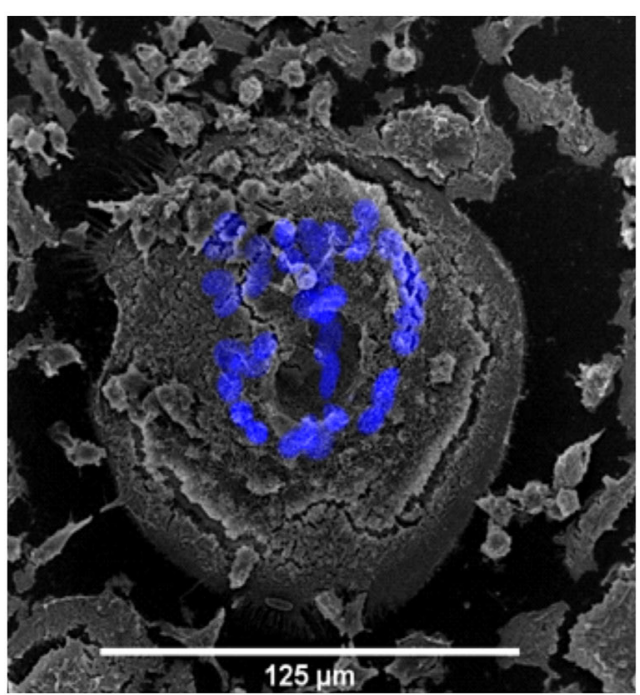

$\mathbf{B}$
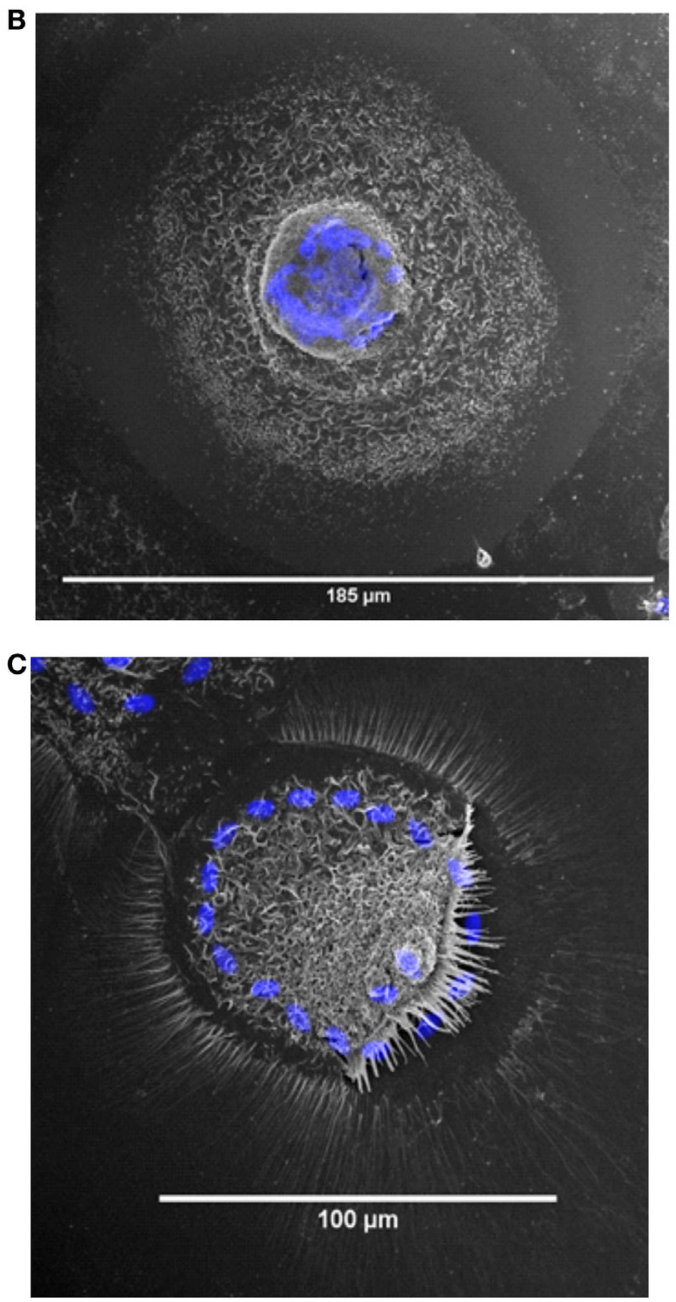
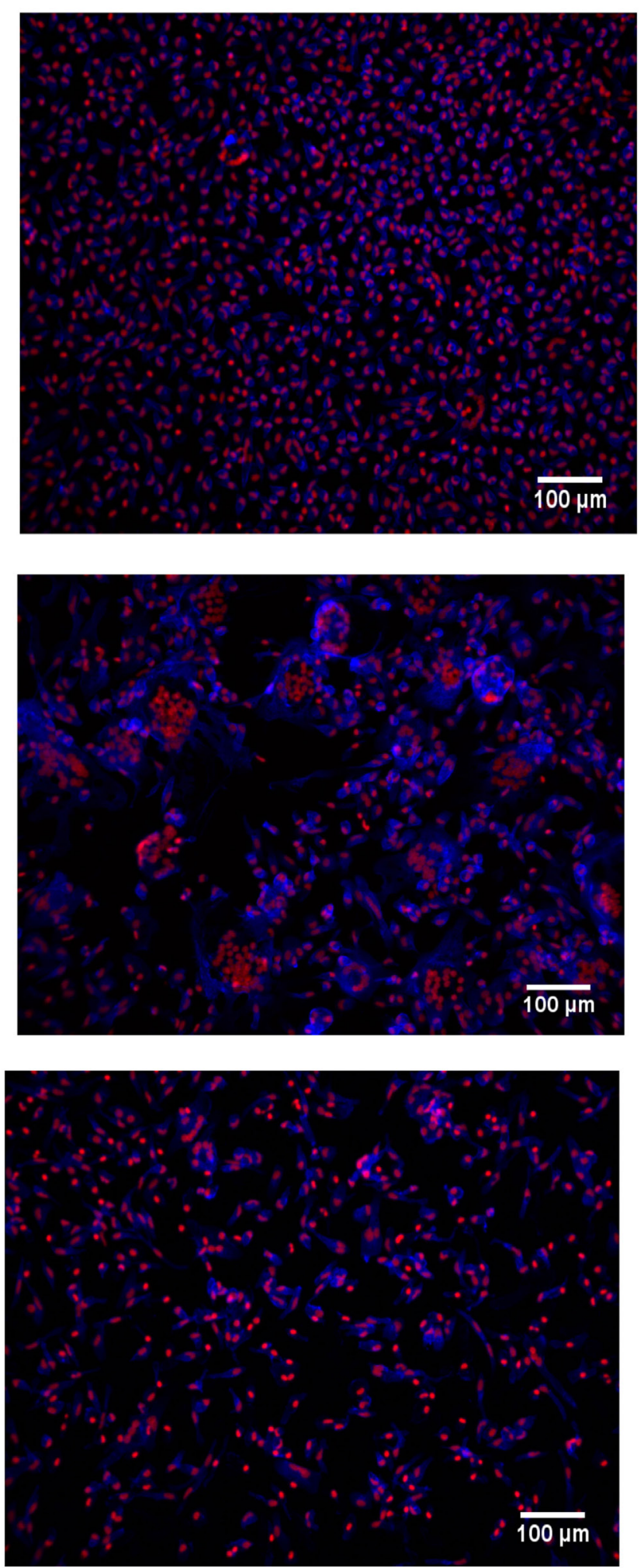

FIGURE 2 | Fusion in different monocyte subsets imaged by tandem fluorescent scanning electron microscopy (SEM) and wide field fluorescence microscopy. (A-C) left panels. monocyte-derived giant cell (MGC) were generated by 72-h concanavalin A (ConA) treatment of FACS-sorted monocyte subsets, stained with Hoechst and then raster-scanned so that the MGC imaged in SEM could be located and the nuclear channel overlaid onto the image. Nuclei shown in blue. (A-C) right panels. Three representative montages containing images taken of each of the monocyte subsets from one donor after $72 \mathrm{~h}$ ConA treatment. Blue = F-actin, Red = nuclei. (A) classical, (B) intermediate, (C) non-classical subset-derived MGC. 
The MGC were classified as LGC, FBGC, or SGC based on the arrangement of nuclei within each MGC according to the criteria shown in Figure S2 in Supplementary Material. Representative wide field and tandem fluorescence-SEM images of fused monocytes formed after $72 \mathrm{~h}$ are shown for each subset in Figure 2. There are distinct differences in the sizes and morphologies of the MGC (Figure 2), suggesting subset-specific factors in MGC formation. Interestingly, the monocyte purification method, i.e. adherence or positive purification by MACS using anti-CD14 strongly affected MGC formation in response to ConA. Despite a similar median number of nuclei observed per MGC, MACSpurified monocytes formed significantly larger MGC than
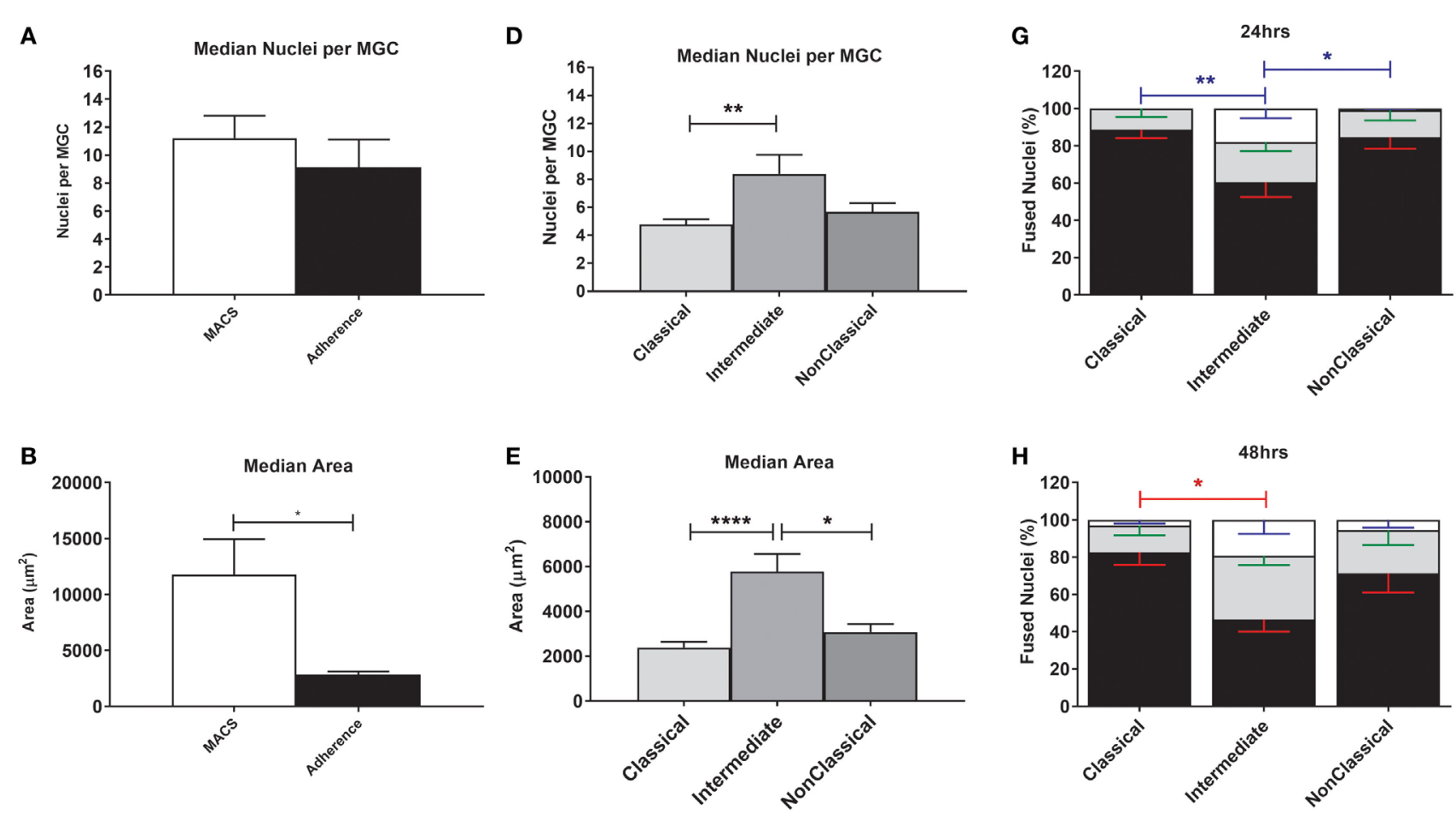

C

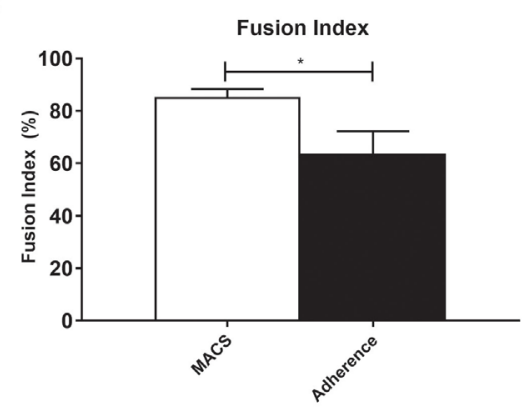

$\mathbf{F}$

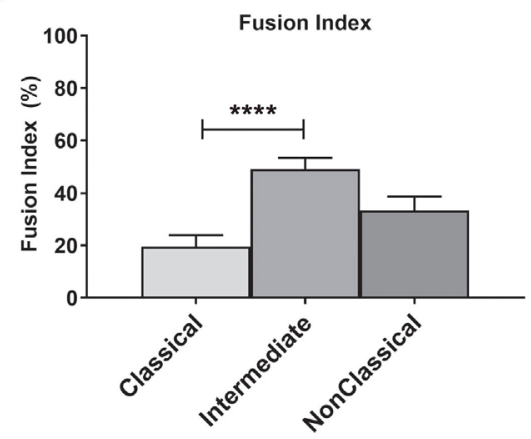

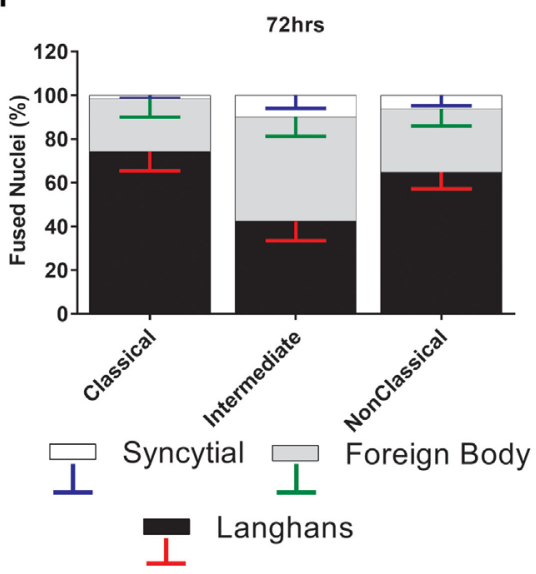

FIGURE 3 | Fusion parameters vary between monocyte purification method and between subsets. (A-C) Unfractionated monocytes, purified by magnet-activated cell sorting (MACS) or adherence were incubated for $72 \mathrm{~h}$ with concanavalin A (ConA) to induce fusion. After fluorescence imaging, three parameters of monocytederived giant cell (MGC) were recorded: median number of nuclei/MGC, fusion index (FI), and median area occupied by each MGC. Significance was tested using an unpaired $t$-test. (D-F) Monocytes sorted into subsets by FACS were incubated for $72 \mathrm{~h}$ with ConA to induce fusion. After fluorescence imaging, three parameters of MGC were recorded: median number of nuclei/MGC, Fl and median area occupied by each MGC. Significance was tested with a Kruskal-Wallis test with a Dunn's multiple comparisons test. (G-I) After 24, 48, and $72 \mathrm{~h}$ incubation with ConA, the proportions of each type of MGC were recorded and presented as a percentage of the total fused nuclei counted. Bars represent means \pm SEM, $n=8$. Significance was tested with a Kruskal-Wallis test with a Dunn' multiple comparisons test comparing the means of the same MGC type within the same time point against the other subset means. Black bars/red error bars: Langhans giant cell, gray bars/green error bars: FBGC and white bars/blue error bars: syncitial giant cell (SGC). 
adherence-purified monocytes, as determined by the median area and FI (Figures 3A-C).

The physical parameters of the MGC formed by monocyte subsets were assessed at $72 \mathrm{~h}$. FI is significantly higher for Int relative to $\mathrm{Cl}$ monocytes, as is the median number of nuclei per MGC (Figures 3D-F), while Int and $\mathrm{NCl}$ subsets were similar for both measurements. Interestingly, the median area covered by each MGC is higher for Int monocytes relative to the other two subsets, perhaps related to the higher percentages of FBGC and SGC observed in Int cultures (Figures 3G,H). At $24 \mathrm{~h}$, the Int monocytes formed significantly more SGC (Figure 3G) whereas at $48 \mathrm{~h}$ of ConA stimulation, they were significantly less likely to form LGC than $\mathrm{Cl}$ monocytes (Figure $3 \mathbf{H}$ ). By $72 \mathrm{~h}$, no significant difference in the types of MGC formed was observed between the subsets (Figure 3I). Thus, there are quantitative differences between the MGC formed by the subsets, in terms of the kinetics of fusion, the sizes, and morphologies of the MGC formed.

\section{Tetraspanin Expression on Monocyte Subsets}

Tetraspanins, particularly CD9, CD81, CD151, and CD63, have been associated with cell fusion in monocytes, developing muscle, and during fertilization (43). We therefore measured the plasma membrane expression of seven common tetraspanins in the freshly purified subsets (Figures 4A,B). The surface expression of tetraspanins on the monocyte subsets shows wide variation, with CD9 and CD37 significantly more highly expressed in the Int subset, in terms of absolute expression levels (MFI) and CD37 is more widely expressed in Int monocytes when expressed as a percentage of the population of cells. After $4 \mathrm{~h}$ ConA treatment of adherent monocytes, the expression of all of some of the tetraspanins (CD53, CD82, and in percent positive cells, CD37) declines (Figures 4C,D). In terms of the expression per cell, the MFI values for CD53 and CD82 decrease significantly in all subsets. Interestingly, expression of CD9, often thought to be a negative regulator of fusion and so expected to decrease after ConA treatment, showed no significant changes in any of the subsets (Figures 4C,D). We also identified a population of CD $9^{\text {High }}$ cells in the unstimulated $\mathrm{Cl}$ subset. Typically, $\sim 75 \%$ of $\mathrm{Cl}$ monocytes were $\mathrm{CD} 9^{\text {Low }}$ and $~ 23 \%$ CD9 $9^{\text {High }}$ (Figure $5 \mathrm{~A}$ ). Examining the co-expression of other tetraspanins with CD9, the dot-plots show an apparent degree of correlation and statistical analysis confirms that CD151 is significantly elevated in CD9 ${ }^{\text {High }}$ $\mathrm{Cl}$ monocytes (Figures 5B,C). However, when sorted, CD9 ${ }^{\text {High }} \mathrm{Cl}$ monocytes did not show a different ability to fuse compared to CD9 ${ }^{\text {Low }} \mathrm{Cl}$ monocytes (data not shown).

\section{Effects of Anti-Tetraspanin Antibodies on MGC Formation}

Anti-tetraspanin antibodies have previously been shown to either positively (anti-CD9, anti-CD81) or negatively (anti-CD63, antiCD151) affect the size of MGC formed by fusing monocytes (40-42), although the contribution of the different subsets and
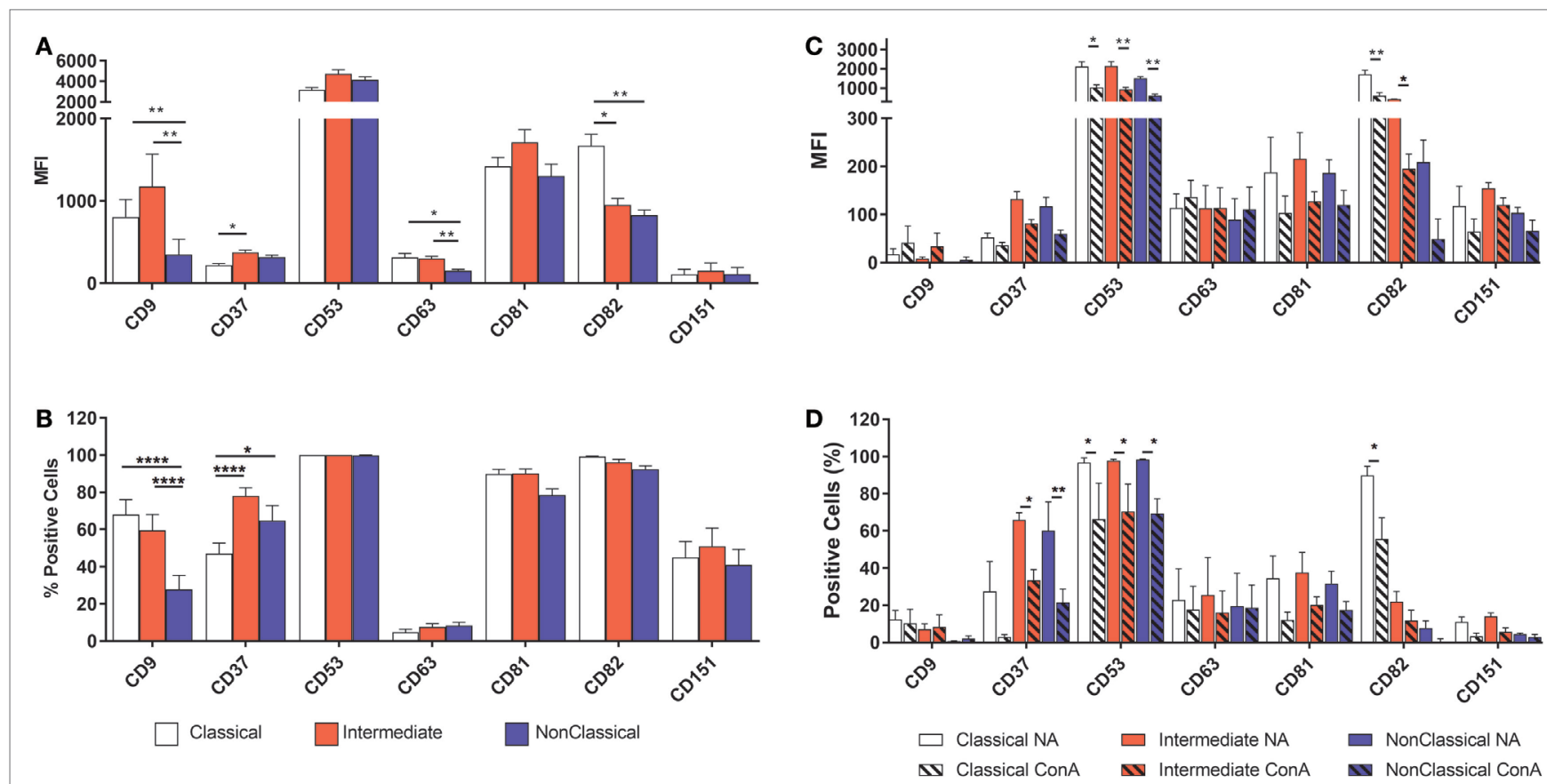

FIGURE 4 | Tetraspanin expression varies between monocyte subsets. Monocytes were either freshly sorted into subsets by FACS, or were purified then allowed to adhere, incubated for $4 \mathrm{~h}$ with concanavalin $\mathrm{A}(\mathrm{ConA})$ to induce fusion and then harvested, before being tested for the expression of a panel of common myeloid cell tetraspanins using flow cytometry. (A) Freshly purified monocyte subsets, expression level per cell (MFI). (B) Freshly purified monocyte subsets, percentage of the cell population with expression above isotype control binding levels. (C) Adherent, ConA treated monocytes, expression level per cell (MFI). (D) Adherent, ConA treated monocytes, percentage of the cell population with expression above isotype control binding levels. The data are the means \pm SEM of monocytes from four donors. For (A,B), significance was tested by two-way ANOVA and a Tukey multiple comparison test. For (C,D), significance was tested with multiple $t$ tests with Benjami, Krieger, and Yekutieli false discovery rate approach and Holme-Sidak multiple comparisons. 

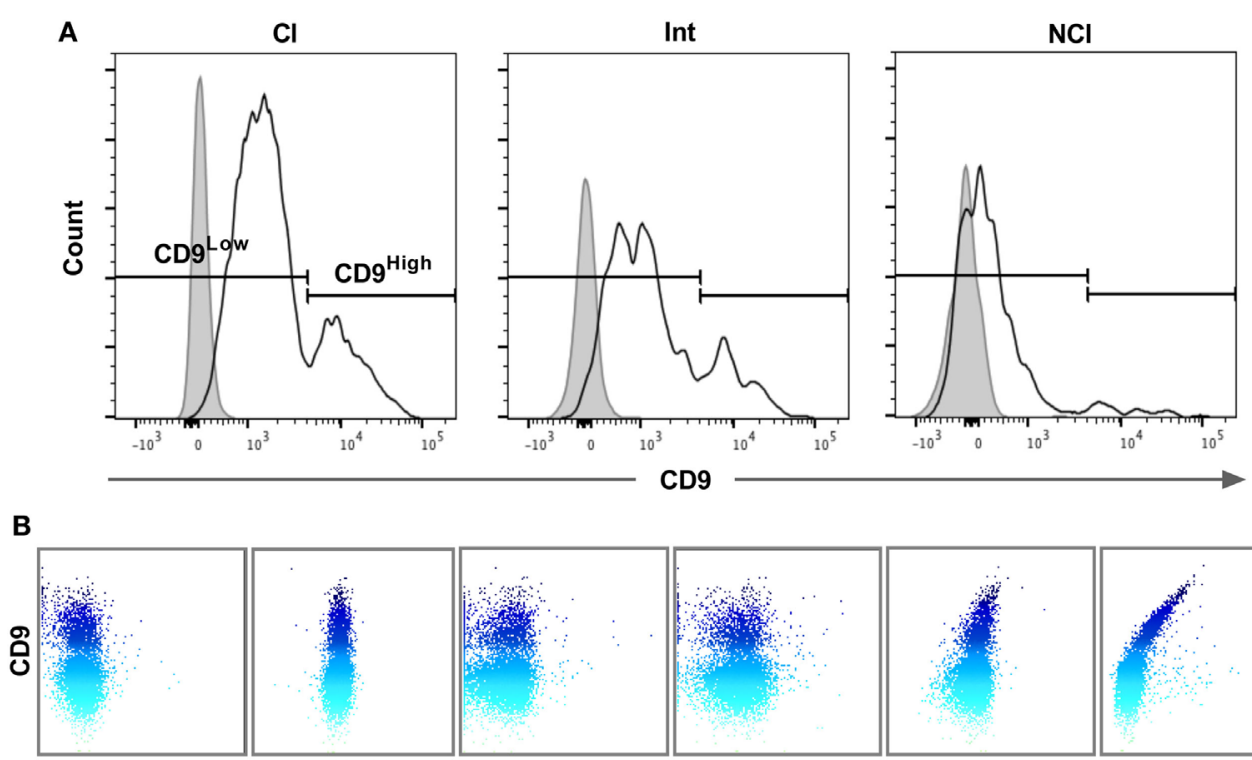

CD37
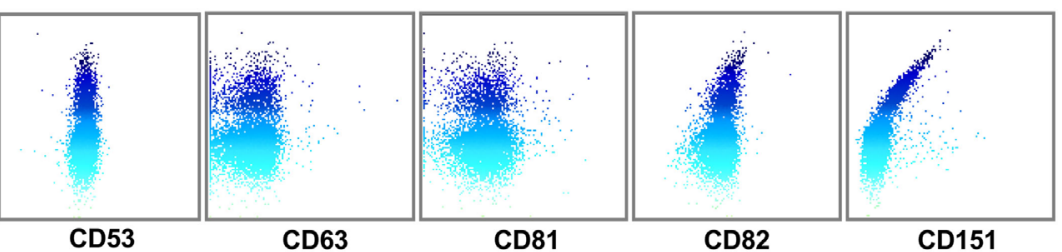

C

Cellular expression of tetraspanins

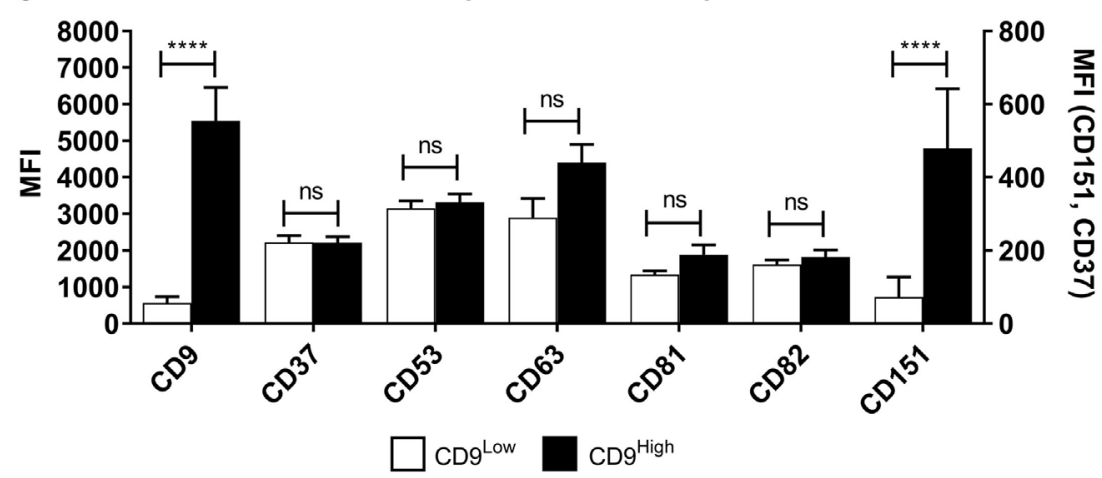

FIGURE 5 | A tetraspanin CD9High subset of classical monocytes. (A) Histograms showing the expression of CD9 on freshly isolated classical (Cl), intermediate (Int), and non-classical (NCl) monocyte subsets from a representative donor, with isotype control fluorescence shown as shaded areas. The gating strategy to separate the CD9 High and CD9 ${ }^{\text {Low }}$ populations is indicated by the markers. CD9 was the only tetraspanin in the histograms to show a bimodal peak of expression. (B) Dot-plots showing the surface co-expression of tetraspanins on classical subset monocytes with CD9 from a representative donor. Increasing expression of CD9 is indicated by the blue shading. (C) Quantification of tetraspanin expression on Cl subset monocytes gated for CD9 high and low expression as shown in panel A. Bars represent the means \pm SEM, from 10 different donors. Significance was tested using one-way ANOVA with Sidak's multiple comparisons test for each pair of columns.

the types of MGC formed have not been analyzed before. Here, we have used a range of anti-tetraspanin antibodies to investigate their contribution to subset- and MGC type specific effects during monocyte fusion (Table S1B in Supplementary Material). First, we investigated the effects of antibodies on the fate of seeded cells (Figure 6). None of the tetraspanin antibodies caused a significant increase in cell detachment, suggesting that any effects on fusion were not caused by changes in cellular adherence or survival. However, several antibodies (against CD9, CD53, CD63, and CD151) did show a trend toward increased cell detachment.

Strikingly, the proportions of each type of MGC produced by fusion of Int monocytes were changed by the anti-tetraspanin antibodies used here (Figure 7) whereas $\mathrm{Cl}$ and $\mathrm{NCl}$ subsets were not affected. Anti-CD63, in particular caused significant changes in the proportions of MGC formed. It inhibited SGC formation completely and promoted a much higher proportion of LGC to FBGC. Anti-CD9, anti-CD53, and anti-CD151 antibodies exhibited similar effects but the changes did not reach significance. Total (unseparated) MACS-purified monocytes were also significantly affected by only anti-CD63. Anti-CD37 antibody also showed a trend toward the inhibition of SGC formation in $\mathrm{Cl}$ and $\mathrm{NCl}$ monocytes. Interestingly, the proportions of the various MGC types formed by unfractionated monocytes did not resemble those formed by the isolated subsets, suggesting that interactions between the monocyte subsets can also affect the type of MGC formed (Figure 7). The adherence-purified monocytes responded only to anti-CD9 antibodies, with higher proportions of larger FBGC and SGC (Figure S3 in Supplementary Material).

With respect to the sizes of the MGC formed, only Int monocytes were affected by treatment with anti-tetraspanin antibodies. 

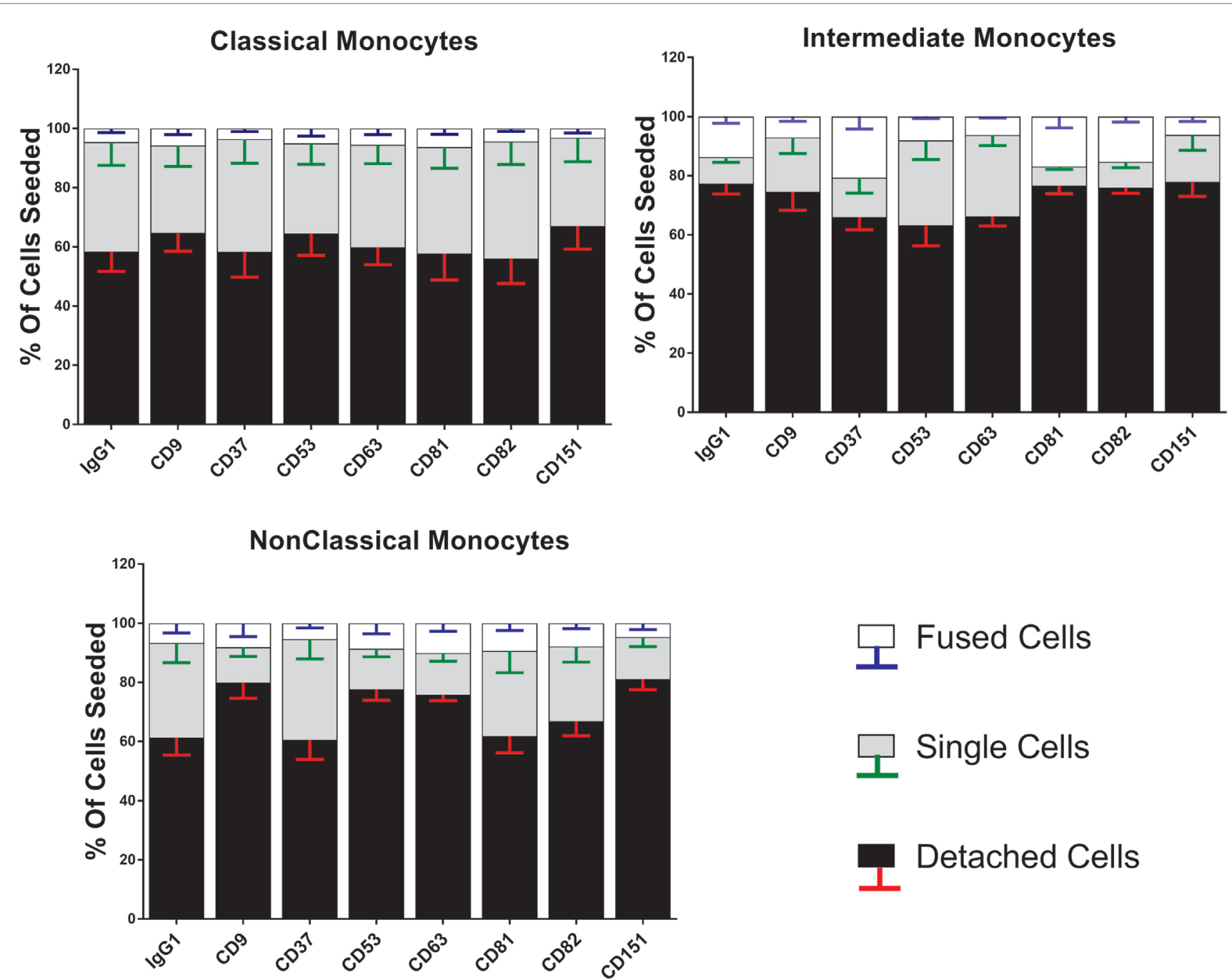

FIGURE 6 | Anti-tetraspanin antibodies do not affect cell fate during concanavalin A (ConA)-induced fusion. The fate of sorted monocyte subsets was determined by counting nuclei at $72 \mathrm{~h}$ and expressed as a percentage of the cell numbers originally plated. Bars represent means \pm SEM, $n=3-8$. Significance was tested with a Kruskal-Wallis test with Dunn's multiple comparisons test comparing the means of the same state within the same time point against the other subsets. Black bars/red error bars: detached cells, gray bars/green error bars: single cells and white bars/blue error bars: fused cells with >3 nuclei.

In contrast to previous data on total monocytes purified by adherence $(40,41)$ and as shown here in Figure S3 in Supplementary Material, anti-CD9 antibodies did not cause an increase in MGC size and have no significant effects on either FI or the number of nuclei per MGC on any of the monocyte subsets. However, anti-CD63 antibodies were found to be consistently inhibitory on all parameters of Int fusion (Figure 8). Anti-CD151 antibody also caused a significant decrease in MGC median area whereas anti-CD53 also inhibited MGC formation but this did not reach significance, $p=0.056$.

\section{Expression of Fusion-Related Molecules on Monocyte Subsets}

Many molecules have been associated with monocyte fusion (26-33) and so we examined a panel of 10 membrane proteins for differential expression on the unstimulated subsets. Int monocytes were clearly enriched for a number of these, including DC-STAMP, CD98 CD17a, and CD200 relative to one or both of the other subsets (Figure 9). This overall pattern of fusion molecule expression might explain the greater propensity of the Int subset to undergo ConA-stimulated fusion.

\section{Cytokine Expression in Fusing Monocytes}

To further investigate the mechanism behind the greater fusogenicity of Int monocytes, we analyzed cytokine production during ConA-mediated fusion to determine if fusogenic cytokine production could contribute to this. ConA-stimulated cytokine production was significantly higher in Int monocytes for IL- $1 \alpha$ and IL- $1 \beta$, confirming the higher pro-inflammatory capacity of this subset (Figure 10). However, other cytokines previously identified as being pro-fusogenic, such as CCL2, IL-4 and IL-13, were not elevated in cultures of Int monocytes when compared to 


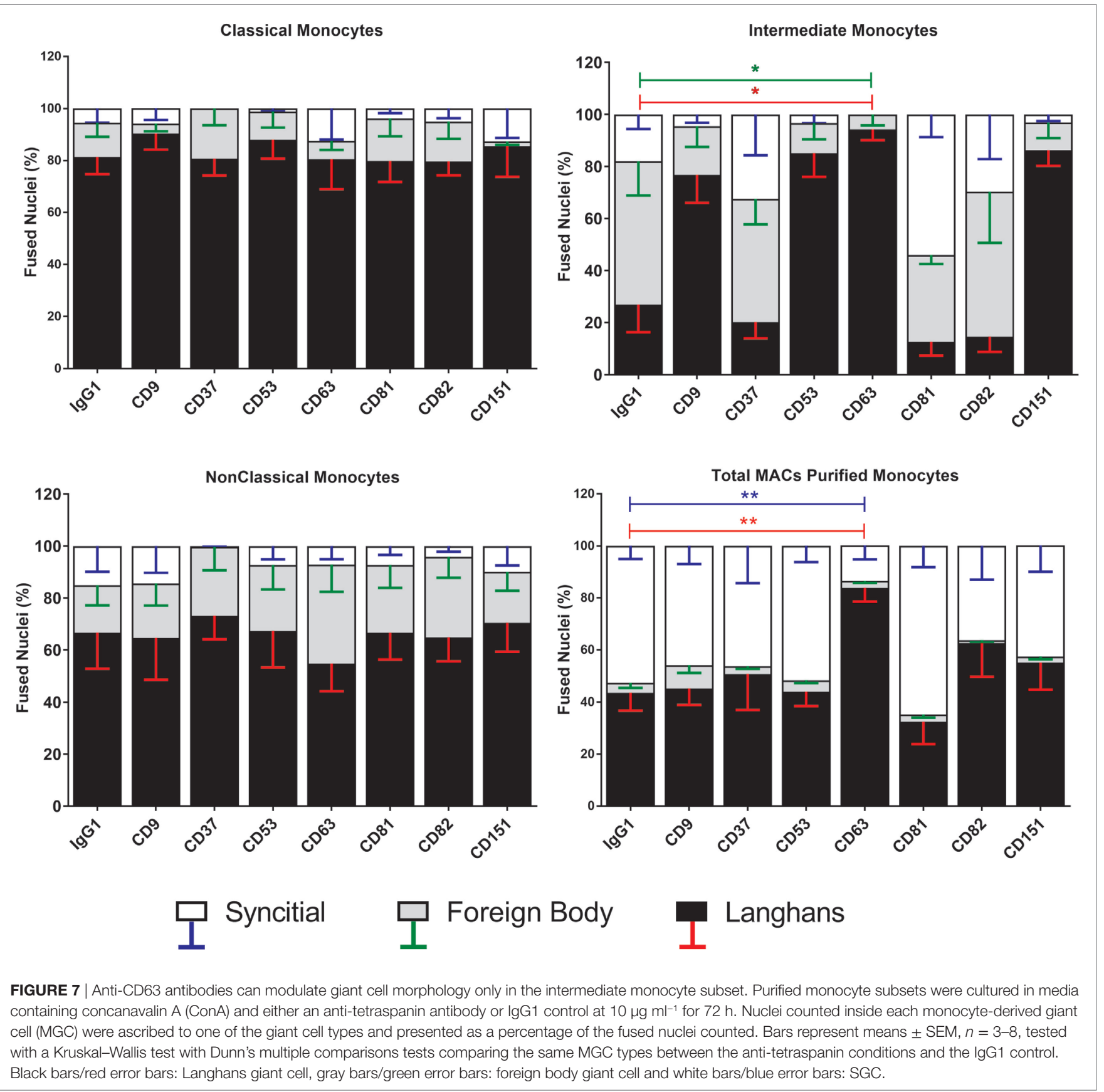

the other two subsets. Thus, the Int monocytes appear to generally secrete higher levels of cytokines but no particular cytokine (of those measured) can be described as playing a pivotal role in the control of MGC formation. IFN $\gamma$, IL-10, IL-17A, CCL5, and VEGF were also tested but were either not detected or were not significantly different from unstimulated controls.

\section{DISCUSSION}

Here, we demonstrate for the first time that human monocyte subsets show very different propensities to form MGC in response to ConA stimulation. The Int subset fused faster and formed more of the larger FBGC and SGC types while the $\mathrm{Cl}$ fused to form mostly the smaller LGC.

\section{Monocyte Purification Methods}

Previous studies on the role of tetraspanins in ConA-induced monocyte fusion used cells purified by adherence $(40,41)$, which have a very different pattern of fusion and anti-tetraspanin antibody sensitivity to the MACS-purified total monocytes used in this report (Figures 3 and 7; Figure S3 in Supplementary Material). The MACS technique specifically enriches monocytes whereas the adherence method relies on the ability of cells to rapidly adhere to plastic surfaces and some contaminating $\mathrm{T}$ 

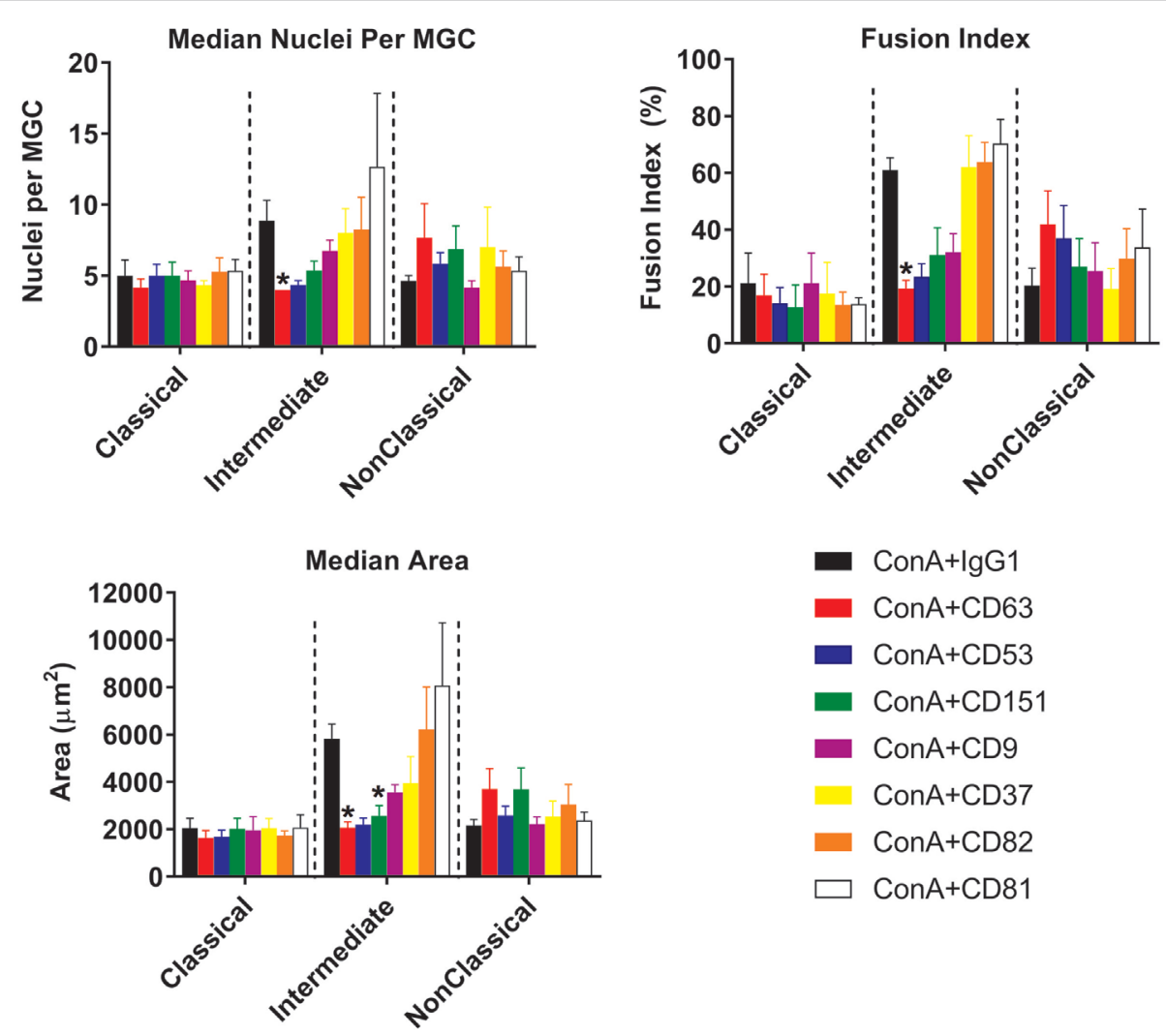

FIGURE 8 | Anti-tetraspanin antibodies inhibit fusion rate and size of giant cells produced by intermediate monocyte subset. Purified monocyte subsets were cultured in media containing (ConA) and either an anti-tetraspanin antibody or lgG1 control at $10 \mu \mathrm{g} \mathrm{m}{ }^{-1}$ for $72 \mathrm{~h}$. Bars represent means \pm SEM, of 3-8 separate experiments. Significance was tested with a Kruskal-Wallis test and a Dunn's multiple comparisons test comparing the anti-tetraspanin antibody means against the lgG1 control within each subset.

and $\mathrm{NK}$ cells may be present. In addition, Int and $\mathrm{NCl}$ subsets are less adherent than $\mathrm{Cl}$ within the first $24 \mathrm{~h}$ after isolation, and so in the previous studies more of the initially adherent low-fusing $\mathrm{Cl}$ and fewer of the high-fusing Int and NC subsets may have been present. Although Int were observed to be the most fusogenic of the subsets (Figure 3A), total MACS-purified monocytes stimulated with ConA showed even higher fusion parameters with many more FBGC and SGC (Figure 7). This suggests that fusion potency is increased by interaction between the subsets.

\section{Monocytes Subsets and Fusion}

The histological type of MGC formed by each subset has been quantified, with the Int and $\mathrm{NCl}$ showing a greater capacity to form the larger FBGC and SGC types. This has implications for the treatment of medical implant rejection as it is clearly the Int and $\mathrm{NCl}$ subsets that form the larger MGC associated with foreign body rejection. Interestingly, the Int subset is increased in the blood of sarcoidosis patients (15), a condition characterized by granulomas in which FBGC and LGC are present (48). The increased ability of the $\mathrm{Cl}$ subset to form LGC could indicate that they are specialized in responding to mycobacterial infections, as LGC are commonly found in granulomatous infections in vivo (19).

\section{Tetraspanin Expression on Subsets}

Our data for the expression of CD9, CD53, CD63, and CD81 does not correlate directly with that of Tippett and co-workers (44), who observed higher percentages of cells expressing CD9 and CD63 overall in each subset. Furthermore, they ranked the intensity of surface expression of CD9 on the subsets as $\mathrm{Cl}>$ Int $>\mathrm{NCl}$, $\mathrm{CD} 53$ as $\mathrm{NCl}>\mathrm{Int}>\mathrm{Cl}$, and $\mathrm{CD} 81$ as $\mathrm{NCl}>$ Int $>\mathrm{Cl}$, whereas here all three tetraspanins were found to be highest on the Int subset. However, the CD14/CD16 gating strategy used by Tipett and co-workers may not have been as stringent as here and so the distinction between the subsets may be less clear. In addition, they did not mention any techniques to remove CD16+ NK cells, which overlap with $\mathrm{NCl}$ in $\mathrm{CD} 14^{+} / \mathrm{CD} 16^{+}$populations. Overall, we found the Int subset expressed the highest levels of all tetraspanins in freshly purified monocytes except for CD82, which was significantly higher in the $\mathrm{Cl}$ subset. The addition of ConA induced significant decreases in the level of CD53 and CD82 and a decrease in the percentage of cells expressing CD37, CD53, and CD82. It appears that ConA induces rapid downregulation of these tetraspanins from the cell surface, although there is no obvious correlation with fusion. Other tetraspanins implicated in fusion, such as Tspan13 and Tspan5, show decreased or increased expression, respectively, in response to RANKL stimulation (39). Tarrant and co-workers (49) showed that 

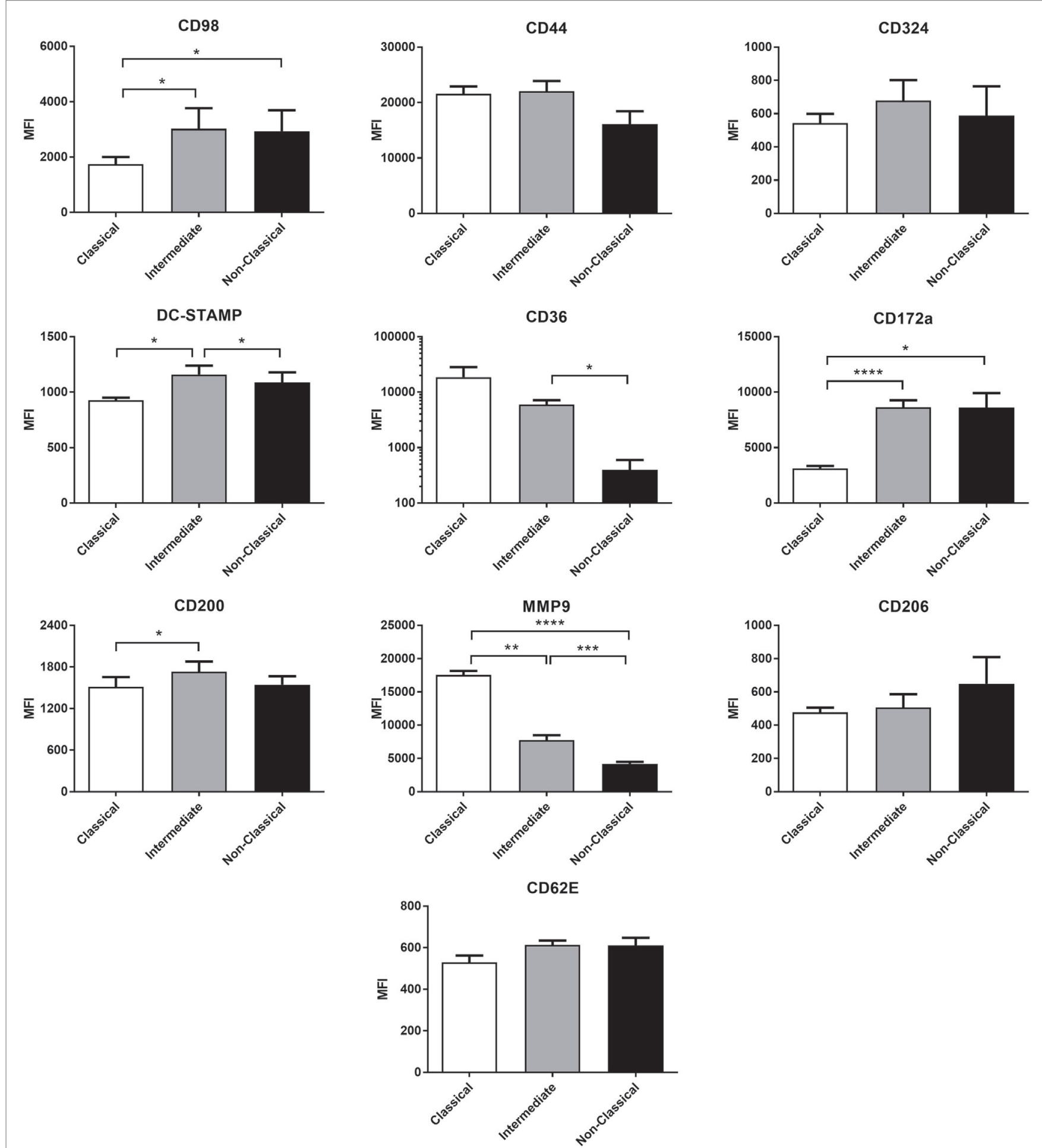

FIGURE 9 | The expression of fusion-related molecules is higher on intermediate monocyte subset. Freshly isolated monocytes were analyzed for fusion protein expression on subsets using flow cytometry. Bars indicate means \pm SD from three separate experiments. Significance of difference between subsets was tested with a one-way ANOVA and a Tukey multiple comparisons test.

Tspan32 knockout mice produced T-cells that became hyperstimulated by ConA. In future studies, it would be interesting to investigate the effects of ConA on further members of the tetraspanin family. The $\mathrm{Cl}$ monocyte subset showed an intriguing bimodal expression of CD9, with nearly $25 \%$ of this subset (and thus $\sim 20 \%$ of total monocytes) having a significantly higher 


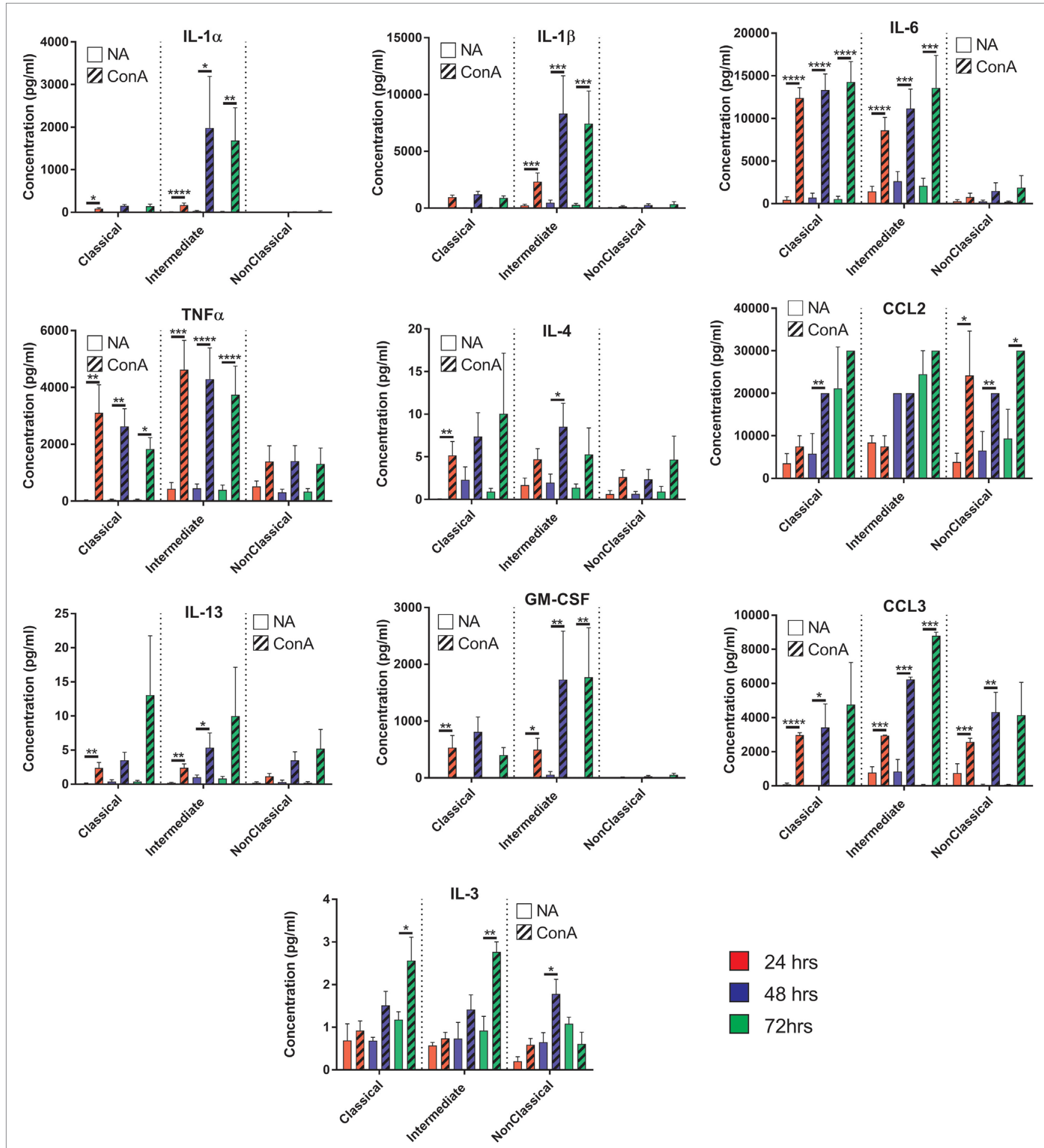

FIGURE 10 | Cytokine production profiles during fusion do not correlate with fusion rate or giant cell morphology. Supernatants from the fusing monocytes were collected and analyzed by ELISA for 15 cytokines relevant to fusion. Clear bars: control (NA), striped bars: concanavalin A (ConA) treated; with each time point [24 (red), 48 (purple), $72 \mathrm{~h}$ (green)] presented in adjacent pairs. Bars represent means \pm SEM, from eight separate experiments, all tested for significance with a twoway ANOVA with a Sidak's multiple comparison test comparing the means of control (NA) vs ConA treated monocytes at the same time point within each subset.

surface expression of this tetraspanin. Co-expression analysis of the tetraspanins showed a positive correlation between CD9 and $\mathrm{CD} 151$ expression on $\mathrm{Cl}$. While $\mathrm{CD} 9^{\mathrm{High}} \mathrm{Cl}$ showed no increase in fusion potential, it would be interesting in future work to investigate other functions of these cells, such as their propensity for extravasation. 


\section{Anti-Tetraspanin Antibodies and Fusion}

The Int subset showed clear significant decreases in fusion parameters and MGC types produced when cultured in the presence of anti-CD63. Anti-CD63 also significantly inhibited MGC formation by total MACS-purified monocytes in response to ConA, in agreement with previous data (41). No inhibition by anti-CD63 was observed for the $\mathrm{Cl}$ and $\mathrm{NCl}$ subsets, however, suggesting that fusion may be orchestrated differently in the subsets. It is also possible that the lower baseline fusion rates of $\mathrm{Cl}$ and the $\mathrm{NCl}$ subsets could be masking any notable reductions by these antibodies. It is not clear from the present work if anti-CD63 treatment is directly affecting cell fusion. CD63 knockdown causes arrested motility due to decreased actin polymerization by engaged E-cadherin (50). Therefore, it is possible that the decrease in fusion is a result of arrested mobility and not interference with the fusion mechanism. The lack of a change in the expression level of CD63 during ConA stimulation suggests that antibody might be modulating function by sequestering CD63 away from partner proteins, for example, or by clustering molecules together to activate signaling. Further work is required to distinguish between these possibilities.

Interestingly, antibodies against CD9, CD53, CD63, and CD151 did show a trend toward increased cell detachment in the $\mathrm{NCl}$ subset and this pattern was also seen in the effects on Int subset MGC types. This suggests that these tetraspanins might have a role in monocyte behavior but that antibodies are not ideal tools to study this role.

\section{Fusion-Related Membrane Proteins}

We hypothesized that increased fusion and sensitivity to antiCD63 antibody in the Int subset might be due to changes in the expression of membrane proteins known to play a role in fusion, many of which are also known to be partners of tetraspanins. The high-fusing Int monocytes showed generally high levels of the fusion-mediating molecules DC-STAMP, CD172a, CD200, and CD62E and low levels of MMP9 and CD36 relative to the other subsets. DC-STAMP, the only molecule significantly higher in Int than in both of the other subsets, has been shown to be essential for cell-cell fusion in osteoclasts and FBGCs (32, 33). CD200, significantly higher in Int than $\mathrm{Cl}$, is expressed in monocytes after the induction of fusion (26). SIRP $\alpha / C D 172 a / M F R$, also higher in Int than $\mathrm{Cl}$, has been shown to be essential for MGC formation (27). MMP9 has been shown to be involved in mouse MGC formation in vivo and in response to IL-4 in vitro (31) but was found here to be significantly lower in Int monocytes than in $\mathrm{Cl}$. CD36, a phosphatidylserine and lipid binding protein, has been shown to have a role in cytokine-induced MGC but not in osteoclast generation (29). Cl and Int monocytes had higher levels of $\mathrm{CD} 36$ than $\mathrm{NCl}$, but as $\mathrm{Cl}$ and $\mathrm{NCl}$ have similarly low fusogenic potential, this suggests that CD36 expression is not specifically related to higher fusion rates in the Int subset. CD62E (E-selectin) has been implicated in osteoclast formation (51) and MGC formation driven by B. pseudomallei infection of U937 cells (30). While it is not significantly more highly expressed in Int monocytes than $\mathrm{Cl}, \mathrm{CD} 62 \mathrm{E}$ is expressed at a similar level on the lower fusing $\mathrm{NCl}$ monocytes. Taken together, however, our data indicate that differences in the expression of multiple fusion-related molecules might be related to the greater fusion capacity of Int monocytes.

\section{Cytokine Production During Fusion}

We hypothesized that different levels of cytokine production during ConA stimulation might play a role in the differences in fusion between subsets but the lack of a clear pattern suggests that this is not the primary driver of the variation between monocyte subsets. However, the subsets do show remarkably different cytokine profiles during fusion. The Int and $\mathrm{Cl}$ secreted proapoptotic cytokines (TNF $\alpha$ ) within the first $24 \mathrm{~h}$ followed by an increase in pro-inflammatory cytokines (IL-1 $\alpha$, IL-1 $\beta$, and IL-6) by $48 \mathrm{~h}$. IL- $1 \alpha$ and IL- $1 \beta$ have been shown to be released from cells undergoing apoptosis (52) and we also observed at these same time points that a large number of monocytes (57-65\%) were dead or detached. This could suggest that many ConA-stimulated monocytes undergo apoptosis and the release of internal IL-1 is a necessary step to generate the fusogenic cytokines. However, the $\mathrm{NCl}$ subset achieved greater fusion rates than the $\mathrm{Cl}$ monocytes but did not release high levels of IL- $1 \alpha$, IL- $1 \beta$, or TNF $\alpha$, suggesting that apoptosis of some cell types is not a pre-requisite for fusion.

In summary, we have shown that the various monocyte subsets differ in their capacity to form MGC in response to ConA, with the Int subset showing greatest propensity for fusion. For this subset, there is evidence that the tetraspanin CD63 may be involved in the process. It is interesting to speculate that the increased fusogenic potential of Int moncytes may relate to their roles in granuloma formation in infectious and inflammatory conditions in vivo.

\section{AUTHOR CONTRIBUTIONS}

PM, LP, and SW planned experiments and wrote the manuscript; $\mathrm{BM}$ and S-MO performed experiments; TC designed and performed experiment and analyzed data.

\section{ACKNOWLEDGMENTS}

The EM facility at the National University of Singapore, Singapore Immunology Network flow cytometry facility for cell sorting, IMB imaging facility, Dr Akhila Balachander for their expertise on microscopy and Dr Marzieh Fanaei for assistance with monocyte fusion assays.

\section{FUNDING}

TC was funded by a studentship from the Biomedical Research Council of the Agency for Science, Technology and research (BMRC-A*STAR), and the University of Sheffield.

\section{SUPPLEMENTARY MATERIAL}

The Supplementary Material for this article can be found online at https://www.frontiersin.org/articles/10.3389/fimmu.2018.01247/ full\#supplementary-material.

FIGURE S1 | FACS gating strategy of monocyte subsets from magnet-activated cell sorting-enriched fraction. Pseudocolour/contour plots showing the FACS gating strategy for sorting monocyte subsets. First, monocytes were broadly selected by their forward and side scatter profiles followed by singlet gating. NK cells were removed by selecting for CD56- cells. Second, CD14++CD16 ${ }^{-}$ 
(Classical), CD14 ${ }^{++} \mathrm{CD} 16^{+}$(Intermediate), and CD14 ${ }^{+} \mathrm{CD} 16^{+}$(non-classical) monocytes were gated as shown and sorted. The purity of the sorted populations was always $>90 \%$.

FIGURE S2 | Morphologies of the three monocyte-derived giant cell (MGC) types observed during fusion assays. A representative low magnification image with nuclei in red and F-actin in blue. Langhans giant cells can be identified by their horseshoe or ring-shaped nuclear arrangement and are typically the smallest. Foreign body giant cells (FBGC) are larger and contain more nuclei in a stacked central cluster. Syncytial giant cells (SGC) are the largest, have

\section{REFERENCES}

1. Auffray C, Sieweke MH, Geissmann F. Blood monocytes: development, heterogeneity, and relationship with dendritic cells. Annu Rev Immunol (2009) 27:669-92. doi:10.1146/annurev.immunol.021908.132557

2. Serbina NV, Jia T, Hohl TM, Pamere EG. Monocyte-mediated defense against microbial pathogens. Annu Rev Immunol (2008) 26:421-52. doi:10.1146/ annurev.immunol.26.021607.090326

3. Wong KL, Yeap WH, Tai JJY, Ong SM, Dang TM, Wong SC. The three human monocyte subsets: implications for health and disease. Immunol Res (2012) 53:41-57. doi:10.1007/s12026-012-8297-3

4. Ziegler-Heitbrock L, Ancuta P, Crowe S, Dalod M, Grau V, Hart DN, et al. Nomenclature of monocytes and dendritic cells in blood. Blood (2010) 116: E74-80. doi:10.1182/blood-2010-02-258558

5. Patel AA, Zhang Y, Fullerton JN, Boelen L, Rongvaux A, Maini AA, et al. The fate and lifespan of human monocyte subsets in steady state and systemic inflammation. J Exp Med (2017) 214:1913-23. doi:10.1084/jem.20170355

6. Tak T, Drylewicz J, Conemans L, de Boer RJ, Koenderman L, Borghans JAM, et al. Circulatory and maturation kinetics of human monocyte subsets in vivo. Blood (2017) 130:1474-7. doi:10.1182/blood-2017-03-771261

7. Wong KL, Tai JJY, Wong WC, Han H, Sem X, Yeap WH, et al. Gene expression profiling reveals the defining features of the classical, intermediate, and nonclassical human monocyte subsets. Blood (2011) 118:E15-30. doi:10.1182/ blood-2010-12-326355

8. Dang TM, Wong WC, Ong SM, Li P, Lum J, Chen JM, et al. MicroRNA expression profiling of human blood monocyte subsets highlights functional differences. Immunology (2015) 145:404-16. doi:10.1111/imm.12456

9. Boyette LB, Macedo C, Hadi K, Elinoff BD, Walters JT, Ramaswamil B, et al. Phenotype, function, and differentiation potential of human monocyte subsets. PLoS One (2017) 12:e0176460. doi:10.1371/journal.pone.0176460

10. Segura V, Valero ML, Cantero L, Munoz J, Zarzuela E, Garcia F, et al. In-depth proteomic characterization of classical and non-classical monocyte subsets. Proteomes (2018) 6:E8. doi:10.3390/proteomes6010008

11. Hadadi E, Zhang B, Baidzajevas K, Yusof N, Puan KJ, Ong SM, et al. Differential IL-1beta secretion by monocyte subsets is regulated by Hsp27 through modulating mRNA stability. Sci Rep (2016) 6:39035. doi:10.1038/srep39035

12. Castano D, Garcia LF, Rojas M. Increased frequency and cell death of CD16+ monocytes with Mycobacterium tuberculosis infection. Tuberculosis (Edinb) (2011) 91:348-60. doi:10.1016/j.tube.2011.04.002

13. Rossol M, Kraus S, Pierer M, Baerwald C, Wagner U. The CD14(bright) CD16+ monocyte subset is expanded in rheumatoid arthritis and promotes expansion of the Th17 cell population. Arthritis Rheum (2012) 64:671-7. doi:10.1002/art.33418

14. Gren ST, Grip O. Role of monocytes and intestinal macrophages in Crohn's disease and ulcerative colitis. Inflamm Bowel Dis (2016) 22:1992-8. doi:10.1097/ MIB.0000000000000824

15. Hofer TP, Zawada AM, Frankenberger M, Skokann K, Satzl AA, Gesierich W, et al. slan-defined subsets of CD16-positive monocytes: impact of granulomatous inflammation and M-CSF receptor mutation. Blood (2015) 126:2601-10. doi:10.1182/blood-2015-06-651331

16. Rogacev KS, Cremers B, Zawada AM, Seiler S, Binder N, Ege P, et al. CD14++CD16+ monocytes independently predict cardiovascular events: a cohort study of 951 patients referred for elective coronary angiography. J Am Coll Cardiol (2012) 60:1512-20. doi:10.1016/j.jacc.2012.07.019

17. Cappellari R, D’Anna M, Bonora BM, Rigato M, Cignarella A, Avogaro A, et al. Shift of monocyte subsets along their continuum predicts cardiovascular heterogeneous spreading of the membrane and unevenly distributed nuclei within.

FIGURE S3 | Monocyte-derived giant cell (MGC) types generated from adherencepurified total monocytes. The MGC types generated from total monocytes purified by adhesion cultured for $72 \mathrm{~h}$ in concanavalin $\mathrm{A}$ (ConA) media and corresponding anti-tetraspanin antibody. Fused nuclei were tallied into either Langhans giant cell, FBGC, or SGC depending on what MGC type they were found in and expressed as a percentage of all fused nuclei. Bars represent the mean \pm SEM, with data from four separate experiments. Tested with a Dunn's multiple comparison test; comparing the mean ranks of each MGC type to the lgG1 + ConA control ( $\left.{ }^{*} \mathrm{p}<0.05\right)$.

outcomes. Atherosclerosis(2017) 266:95-102. doi:10.1016/j.atherosclerosis.2017. 09.032

18. Feng X, Teitelbaum SL. Osteoclasts: new insights. Bone Res (2013) 1:11-26. doi:10.4248/BR201301003

19. Byrd TF. Multinucleated giant cell formation induced by IFN-gamma/IL-3 is associated with restriction of virulent Mycobacterium tuberculosis cell to cell invasion in human monocyte monolayers. Cell Immunol (1998) 188:89-96. doi:10.1006/cimm.1998.1352

20. Anderson JM, Rodriguez A, Chang DT. Foreign body reaction to biomaterials. Semin Immunol (2008) 20:86-100. doi:10.1016/j.smim.2007.11.004

21. Ishii M, Saeki Y. Osteoclast cell fusion: mechanisms and molecules. Mod Rheumatol (2008) 18:220-7. doi:10.1007/s10165-008-0051-2

22. Vignery A. Macrophage fusion: molecular mechanisms. Methods Mol Biol (2008) 475:149-61. doi:10.1007/978-1-59745-250-2_9

23. McNally AK, Anderson JM. Interleukin-4 induces foreign body giant cells from human monocytes/macrophages. Differential lymphokine regulation of macrophage fusion leads to morphological variants of multinucleated giant cells. Am J Pathol (1995) 147:1487-99.

24. Anderson JM. Multinucleated giant cells. Curr Opin Hematol (2000) 7:40-7. doi:10.1097/00062752-200001000-00008

25. Helming L, Gordon S. Molecular mediators of macrophage fusion. Trends Cell Biol (2009) 19:514-22. doi:10.1016/j.tcb.2009.07.005

26. Vignery A. Macrophage fusion: the making of a new cell. In: Larsson LI, editor. Cell Fusions. Dordrecht: Springer (2011). p. 219-31.

27. Vignery A. Osteoclasts and giant cells: macrophage-macrophage fusion mechanism.IntJ ExpPathol(2000)81:291-304.doi:10.1111/j.1365-2613.2000.00164.x

28. Han X, Sterling H, Chen Y, Saginario C, Brown EJ, Frazier WA, et al. CD47, a ligand for the macrophage fusion receptor, participates in macrophage multinucleation. J Biol Chem (2000) 275:37984-92. doi:10.1074/jbc.M002334200

29. Helming L, Winter J, Gordon S. The scavenger receptor CD36 plays a role in cytokine-induced macrophage fusion. J Cell Sci (2009) 122:453-9. doi:10.1242/ jcs.037200

30. Suparak S, Muangsombut V, Riyapa D, Stevens JM, Stevens MP, Lertmemongkolchai $\mathrm{G}$, et al. Burkholderia pseudomallei-induced cell fusion in $\mathrm{U} 937$ macrophages can be inhibited by monoclonal antibodies against host cell surface molecules. Microbes Infect (2011) 13:1006-11. doi:10.1016/j. micinf.2011.06.007

31. MacLauchlan S, Skokos EA, Meznarich N, Zhu DH, Raoof S, Shipley JM, et al. Macrophage fusion, giant cell formation, and the foreign body response require matrix metalloproteinase 9. J Leukoc Biol (2009) 85:617-26. doi:10.1189/ jlb.1008588

32. Yagi M, Miyamoto T, Sawatani Y, Iwamoto K, Hosogane N, Fujita N, et al. DC-STAMP is essential for cell-cell fusion in osteoclasts and foreign body giant cells. J Exp Med (2005) 202:345-51. doi:10.1084/jem.20050645

33. Chiu YH, Mensah KA, Schwarz EM, Ju Y, Takahata M, Feng C, et al. Regulation of human osteoclast development by dendritic cell-specific transmembrane protein (DC-STAMP). J Bone Miner Res (2012) 27:79-92. doi:10.1002/ jbmr.531

34. Sabetian S, Shamsir MS, Abu Naser M. Functional features and protein network of human sperm-egg interaction. Syst Biol Reprod Med (2014) 60:329-37. doi:10.3109/19396368.2014.955896

35. Charin S, Latil M, Soave S, Polesskaya A, Chretien F, Bouchiex C, et al. Normal muscle regeneration requires tight control of muscle cell fusion by tetraspanins CD9 and CD81. Nat Commun (2013) 4:1674. doi:10.1038/ncomms2675

36. Pique C, Lagaudriere-Gesbert C, Delamarre L, Rosenberg AR, Conjeaud $\mathrm{H}$, Dokhelar MC. Interaction of CD82 tetraspanin proteins with HTLV-1 
envelope glycoproteins inhibits cell-to-cell fusion and virus transmission. Virology (2000) 276:455-65. doi:10.1006/viro.2000.0538

37. Singethan K, Muller N, Schubert S, Luttge D, Krementsov DN, Khurana SR, et al. CD9 clustering and formation of microvilli zippers between contacting cells regulates virus-induced cell fusion. Traffic (2008) 9:924-35. doi:10.1111/j.1600-0854.2008.00737.x

38. Ishii M, Iwai K, Koike M, Ohshima S, Kudo-Tanaka E, Ishii T, et al. RANKLinduced expression of tetraspanin CD9 in lipid raft membrane microdomain is essential for cell fusion during osteoclastogenesis. J Bone Miner Res (2006) 21:965-76. doi:10.1359/jbmr.060308

39. Iwai K, Ishii M, Ohshima S, Miyatake K, Saeki Y. Expression and function of transmembrane-4 superfamily (tetraspanin) proteins in osteoclasts: reciprocal roles of Tspan-5 and NET-6 during osteoclastogenesis. Allergol Int (2007) 56:457-63. doi:10.2332/allergolint.O-07-488

40. Takeda Y, Tachibana I, Miyado K, Kobayashi M, Miyazaki T, Funakoshi T, et al. Tetraspanins CD9 and CD81 function to prevent the fusion of mononuclear phagocytes. J Cell Biol (2003) 161:945-56. doi:10.1083/jcb.200212031

41. Parthasarathy V, Martin F, Higginbottom A, Murray H, Moseley GW, Read RC, et al. Distinct roles for tetraspanins CD9, CD63 and CD81 in the formation of multinucleated giant cells. Immunology (2009) 127:237-48. doi:10.1111/j.1365-2567.2008.02945.x

42. Hulme RS, Higginbottom A, Palmer J, Partridge LJ, Monk PN. Distinct regions of the large extracellular domain of tetraspanin CD9 are involved in the control of human multinucleated giant cell formation. PLoS One (2014) 9:e116289. doi:10.1371/journal.pone.0116289

43. Fanaei M, Monk PN, Partridge LJ. The role of tetraspanins in fusion. Biochem Soc Trans (2011) 39:524-8. doi:10.1042/BST0390524

44. Tippett E, Cameron PU, Marsh M, Crowe SM. Characterization of tetraspanins CD9, CD53, CD63, and CD81 in monocytes and macrophages in HIV-1 infection. J Leukoc Biol (2013) 93:913-20. doi:10.1189/jlb.0812391

45. Neron S, Thibault L, Dussault N, Cote G, Ducas E, Pineault N, et al. Characterization of mononuclear cells remaining in the leukoreduction system chambers of apheresis instruments after routine platelet collection: a new source of viable human blood cells. Transfusion (2007) 47:1042-9. doi:10.1111/j.1537-2995.2007.01233.x
46. Halfer C, Petrella L. Cell fusion induced by lysolecithin and concanavalin A in Drosophila melanogaster somatic cells cultured in vitro. Exp Cell Res (1976) 100:399-404. doi:10.1016/0014-4827(76)90166-X

47. Sodhi A, Kesherwani V. Production of TNF-alpha, IL-1beta, IL-12 and IFNgamma in murine peritoneal macrophages on treatment with wheat germ agglutinin in vitro: involvement of tyrosine kinase pathways. Glycoconj $J$ (2007) 24:573-82. doi:10.1007/s10719-007-9054-z

48. Okamoto H, Mizuno K, Horio T. Circulating CD14(+) CD16(+) monocytes are expanded in sarcoidosis patients. J Dermatol (2003) 30:503-9. doi:10.1111/ j.1346-8138.2003.tb00424.x

49. Tarrant JM, Groom J, Metcalf D, Li R, Borobokas B, Wright MD, et al. The absence of Tssc6, a member of the tetraspanin superfamily, does not affect lymphoid development but enhances in vitro $\mathrm{T}$-cell proliferative responses. Mol Cell Biol (2002) 22:5006-18. doi:10.1128/MCB.22.14.5006-5018.2002

50. Seubert B, Cui H, Simonavicius N, Honert K, Schafer S, Reuning U, et al. Tetraspanin CD63 acts as a pro-metastatic factor via beta-catenin stabilization. Int J Cancer (2015) 136:2304-15. doi:10.1002/ijc.29296

51. Mbalaviele G, Chen H, Boyce BF, Mundy GR, Yoneda T. The role of cadherin in the generation of multinucleated osteoclasts from mononuclear precursors in murine marrow. J Clin Invest (1995) 95:2757-65. doi:10.1172/JCI117979

52. Hogquist KA, Nett MA, Unanue ER, Chaplin DD. Interleukin 1 is processed and released during apoptosis. Proc Natl Acad Sci U S A (1991) 88:8485-9. doi:10.1073/pnas.88.19.8485

Conflict of Interest Statement: The authors declare that the research was conducted in the absence of any commercial or financial relationships that could be construed as a potential conflict of interest.

Copyright $\odot 2018$ Champion, Partridge, Ong, Malleret, Wong and Monk. This is an open-access article distributed under the terms of the Creative Commons Attribution License (CC BY). The use, distribution or reproduction in other forums is permitted, provided the original author(s) and the copyright owner are credited and that the original publication in this journal is cited, in accordance with accepted academic practice. No use, distribution or reproduction is permitted which does not comply with these terms. 